\title{
PENGEMBANGAN BAHAN AJAR PADA PELATIHAN MEMBATIK BERBASIS BUDAYA LOKAL
}

\author{
Agusti Efi ${ }^{1 *}$, Nita Sahara ${ }^{2 *}$ \\ Program Studi Pendidikan Kesejahteraan Keluarga, Jurusan Ilmu Kesejahteraan Keluarga \\ Fakultas Pariwisata dan Perhotelan \\ Universitas Negeri Padang \\ Jl. Prof. Dr. Hamta, Air Tawar Padang, Kel. Air Tawar Barat, Kec. Padang Utara, Kota Padang, Kode Pos 25171 \\ Sumatera Barat. Indonesia \\ Email:gustti@yahoo.co.id
}

\begin{abstract}
Abstrak
Penelitian ini berdasarkan pengembangan bahan ajar yang digunakan untuk pelatihan membatik pada programPPPUD UNP 2019, dengan judul "Pengembangan Kerajinan Batik Berbasis Budaya Lokal di Kabupaten AgamSumatera Barat, Menuju Pasar Global". Hal ini dilaksanakan, seiring dengan usaha pemerintah daerah yang mendorong industri batik tumbuh dan berkembang di Sumatera Barat, salah satunya adalah UMKM Batik Minang Alam Takambang yang berlokasi di Nagari Batu Palano Kec. Sungai Puar Kab. Agam, Propinsi Sumatera Barat yang menjadi mitra dalam PPPUD UNP. Sebagai unggulan daerah UMKM Batik Minang Alam Takambangharusdidoronguntukdapat berkembangsama dengan batik lainnya yang telah dahulu maju di pulau Jawa. Metode dalam mengembangkan bahan ajar ini adalah Research and Development dengan model penelitian 4D yang terdiri dari tahap pendefinisian, tahap perencanaan, tahap pengembangan dan tahap penyebaran. Bahan ajar yang dikembangkan dianggap telah dapat digunakan oleh peserta pelatihan membatik dalam proses belajar, berdasarkan hasil penelitian data uji validitas dan praktikalitas, dengan hasil 83,35\% kategori sangat valid. Sedangkan data uji praktikalitas dengan hasil 85,89\% kategori sangat praktis. Dapat disimpulkan bahwa bahan ajar batik tulis layak digunakan sebagai media pembelajaran pada mata kuliah analisis tekstil.
\end{abstract}

Kata Kunci: bahan ajar, pelatihan, membatik, budayalokal.

\begin{abstract}
This research is based on the development ofteaching materials usedfor batik training in the 2019 PPP UNP PPPUD program, entitled "Development of Local Culture-Based Batik Crafts in Agam Regency, West Sumatra, Towards a Global Market". This was carried out, along with the efforts of the local government to encourage the batik industry to grow and develop in West Sumatra, one of which was the Minangkabau Batik Minang Alam Takambang located in Nagari Batu Palano Kec. Sungai Puar Kab. Agam, West Sumatra Province which is a partner in PPPUD UNP. As the pre-eminent regional SME Batik Minang Alam Takambang should be encouraged to be able to develop together with other batik that had previously advanced on the island of Java. The method in developing this teaching material is Research and Development with the 4D research model consisting of the defining stage, the planning stage, the development stage and the deployment stage. Teaching materialdeveloped is considered to be able to be used by batik training participants in the learning process, based on the results of the validity and practicalitytest data, with the results of $83.35 \%$ the category is very valid. While the practicality test data with the results of $85.89 \%$ is very practical category. It can be concluded that the written batik teaching material is fit to be used as a learning medium in textile analysis courses.
\end{abstract}

Keywords: teaching materials, training, batik, local culture.

\section{PENDAHULUAN}

Teknik membatik batik tulis pada dasarnya adalah teknik menulis diatas kain dengan menggunakan media malam dan canting, adajuga yang mengatakan melukis diatas kain. 1) hal ini dikatakan juga bahwa membatik merupakan teknik pembuatan desain (gambar) pada permukaan kain dengan cara menutupi bagian-bagian tertentu dengan mengunakan lilin/malam, setelah selesi baru diberi warna dengan cara dicelup atau dicolet memakai kuas.

Proses membatik Batik adalah suatu karya seni halus yang dikerjakan dengan tangan, oleh sebab itu pertu kesabaran. 2) "tidak semua orang mampu melakukan pekerjaan membatik karena membatik perlu kes abaran dan ketelatenan. Karena membatik itu sendiri pada das arnya mengembangkan titik-titik menjadi menjadi 
motif sehingga melahirkan kriya yang berkualitas tinggi”. Untuk mengembangkan kriya batik tidak terikat pada motif tertentu saja atau motif-motif yang sudah ada sebelumnya, berbagai motif lokal dapat dikembangkan menjadi motif batik.

Untuk mengembangkan motif baru berbas is budaya lokal, perlu pemahaman terhadap seni dan estetika tradisi, serta kemampuan teknikaldan es tetika. Desain batik sebagai bagian dari seni tradisi sangat dipengaruhi oleh seni dan adat is tiadat yang berlaku. Faktor agama dan kepercayaan yang dianut juga ikut berperan dalam menentukan bentuk dan karakter seni batik yang dihasilkan sebagai benda rupa. 3)"Kriya batik juga tidak dapat dipisahkan dengan budaya agama seperti yang terlihat dalam motifnya yang dipengaruhi oleh Hindu dan Is lam, budaya Cina dan Eropa; tetapi sekaligus pada saat yang sama agama tidak membatasi kehadiran berbagai motif'. Oleh sebab itu bila ingin melakukan inovasi batik berbasis budaya lokal, maka sebagai dasar pengembangan harus berpijak pada nilai-nilai filos ofi masyarakat, yang merupakan perpaduan konsep agama, kepercayaan dan budaya dimana batik itu ingin dikembangkan.

Namun dalam pengembangan batik yang ada di Sumatera Barat agak lambat, karena dalam budaya masyarakat Sumatera Barat belum ditemukan kriya batik yang benar-benar mengakar dalam kehidupan masyarakatnya. Masyarakat Sumatera Barat pada umumnya adalah masyarakat agraris, pengembangan seni batik merupakan seni baru bagi mereka. Oleh sebab itu dari segi teknik dan keterampilan membatik perlu dilakukan pelatihan-pelatihan untuk menciptakan sumberdaya. Demikian juga dengan pengembangan ragam hias batik, pada industri kecil yang ada di Sumatera Barat, belum tampak pemanfaatan motifmotif yang adadi Sumatera Barat, bahkan yang banyak dikembangkan adalah gambar rumah adat y ang mereka sebut rumah gadang, padahal dalam rumah gadang terdapat berbagai motif-motif yang dapat dikembangkan menjadi motif batik.

Oleh sebab itu telah dilakukan pengembangan bahan ajar yang dapat digunakan dalam pelatihan-pelatihan membatik dan dapat digunakan dalam belajar secara mandiri. Bahan ajar merupakan salah satu bagian penting dalam proses pembelajaran. 4) "dalam bahan ajar terdapat berbagai matera ajar terkait dengan apa yang diajarkan dan dapat dijadikan sumber ajar yang mengandung pesan pembelajaran, yang dapat dimanfaatkan untuk kepentingan pembelajaran.
Gorga : Jurnal Seni Rupa

Volume 09 Nomor 01 Januari-Juni 2020

p-ISSN: 2301-5942 | e-ISSN: 2580-2380

Maka modul pembelajar batik yang dikembangkan sebagai bahan ajar dalam pelatihan dibuat sesuai dengan kepentingan belajar dilapangan. 5) " maka unutuk pelatihan bahan ajar memuat materi pelatihan yang disusun secara sistematis, mempunyai struktur dan urutan yang sistematis, agar mudah di ikuti dan dipelajar oleh peserta pelatihan, sehingga kesukarankesukaran yang mereka temui tidak menjadi hambatan dalam belajar".

Oleh sebab itu pengembangan bahan ajar pada pelatihan membatik yang dapat digunakan oleh pengerajin batik di Sumatera Barat perlu memuat materi utama: pengenalan seni batik, teknik membatik dan pengembangan ragam hias Minangkabau (Sumatera Barat) menjadi ragam hias seni Batik. Metode yang digunakan dalammeng embangkan modul ini Research and Development ( $R \& D)$. (6)"Kegiatan dimulai dengan research untuk mendapatkan informasi tentang kebutuhan pengguna (need assesment) dan dilanjutkan dengan development untuk menghasilkan produk baru. (7) Produk baru dirancang secara sis tematis kemudian diuji dilapangan, dievaluasi, dan disempurnakan sampai memenuhi kriteria tertentu yaitu valid dan praktis. (8) "Ada empat tahap dalam model pengembangan ini yaitu: pendefinisisan (define), perancangan (design), pengembangan (develop), dan penyebaran (dessminate).

Jenis data yang diambil dalampenelitian ini adalahdata primer. Data pertama berupa hasil validasi dari validator. Data kedua dari uji prktikalitas dilakukan dilapangan pada peserta pelatihan. Teknik analisis data berdasarkan analis is validitas dan analis is praktikalitas bahan ajar.

\section{KAJIAN TEORI}

\section{Batik}

Penjelasan tetang batik beraneka ragam dari berbagai pakar dan penulis, Wulandari dalam Dhani (2020: 89) menjelaskan tentang batik dari etimologi katanya beras al dari Bahas a Jawa, "amba" yang berarti lebar, luas, kain, dan "titik" yang berarti titik atau matik (kata kerja membuat titik) yang kemudian berkembang menjadi is tilah batik, yang berarti menghubungkan titik menjadi gambar tertentu padakain yang luas atau lebar. Selanjutnya Prasetyo (2016: 54) mengungkapkan batik dari segi motif, adalah kerangka gambar yang mewujudkan batik secara keseluruhan, kemudian ada juga yang mengatakan bahwa batik merupakan perpaduan antara garis, bentuk, dan is en menjadi satu kesatuan yang mewujudkan batik secarakeseluruhan. 
Selanjutnya pendefenisian tentang batik berikutnya bahwa batik merupakan kain bergambar yang pembuatannya secara khusus dengan menuliskan atau menerapkan malam pada kain itu, kemudian pengolahannya diproses dengan cara tertentu yang memiliki kekhasan (Elliott, 1984). Berdasarkan pendapat ahli di atas maka dapat dibuat kesimpulan bahwa batik adalah lembaran kain yang luas yang di atasnya dibuat sebuah bentuk dengan cara menghubungkan titik dengan penerapan malam diproses dengan kekhasan tertentu. Media yang dikembangkan di sini yakninya tentang batik, dimana media merupakan segala hal yang digunakan untuk menyalurkan pesan, informasi, pengetahuan, dan lain sebagainya (Kartono, 2020: 128).

\section{METODE PELAKSANAAN}

Membatik dimulai dengan membuat desain terlebih dahulu. Desain motif batik yang telah dibuat berdasarkan motif ukiran Minangkabau untuk tahap pertama diolah menjadibatik tulis dan batik cap. Untuk batik tulis desain yang sudah jadilans ung dipindahkan kemori sesuai dengan tata letak motif y ang diharapkan. Sedangkan untuk batik cap desain yang sudah jadi dibuat menjadi stempel cap, sebagai alat untuk memindahkan motif ke mori, dan selanjutnya diolah dengan tehnik batik, sehingga menjadi kain batik. Hasil batik karya inovasi ini ditinjau kembali susunan dan tata letaknya.

\section{HASIL DAN PEMBAHASAN}

\section{Hasil}

\section{1). Uji Validasi Bahan Ajar}

Uji validasi bahan ajar dilakukan oleh Mitra sebagai pakar batik bapak Ismed Muchtar dan dua orang instruktur y ang biasa memberi pelatihan batik yaitu ibu Wiswarti dan bapak Fitra serta satu orang dosen yang mengajar batik di jurusan Seni Rupa UNP, Drs. Erwin A,M.Sn. Hasilvaliditas dapat dilihat pada tabel berikut:

Tabel 1. Hasil Validasi Ahli Materi Bahan Ajar

\begin{tabular}{|c|c|c|c|}
\hline No & Aspek Penilaian & $\begin{array}{c}\text { Hasil Validitas } \\
(\mathbf{\%})\end{array}$ & Kategori \\
\hline 1 & Kelayakan Isi & $87,14 \%$ & Sangat Valid \\
\hline 2 & Penyajian Bahan & $91,11 \%$ & Sangat Valid \\
\hline 3 & Penilaian Bahasa & $86,36 \%$ & Sangat Valid \\
\hline \multicolumn{2}{|c|}{ Rata-Rata } & $\mathbf{8 8 , 2 1} \%$ & Sangat Valid \\
\hline
\end{tabular}

Diuraikan dari hasil validasi ahli materi pada tabel diatas yaitu: 1) kelayakan isi nilai 87,14 kategori sangat valid, 2) penyajian bahan nilai $91,11 \%$ kategori sangat valid, 3) penilaian bahasa $86,36 \%$ kategori s angat valid. Dari 3 as pek penilaian di atas diproleh rata-rata $\mathbf{8 8 , 2 1 \%}$ dengan kategori sangat valid.

\section{2). Praktikalitas Bahan Ajar}

Gorga : Jurnal Seni Rupa

Volume 09 Nomor 01 Januari-Juni 2020

p-ISSN: 2301-5942 | e-ISSN: 2580-2380

Tahap praktikalitas bahan ajarbatik tulis dilakukan uji praktikalitas pada peserta Tahap ini dilakukan dengan menggunakan angket yang diberikan oleh peneliti kemudian diisi oleh responden. Hasil uji praktikalitas kelompok kecil. Uji praktikalitas pada pengerajin kelompokkecil dilakukan kepada 10 pes erta pelatihan. Maka hasil uji praktikalitas sebagai berikut:

Tabel 2. Hasil Uji Praktikalitas Pengerajin/ Peserta Pelatihan Kelompok Kecil

\begin{tabular}{|l|l|c|c|}
\hline No & \multicolumn{1}{|c|}{ Aspek Penilaian } & $\begin{array}{c}\text { Hasil } \\
\text { Praktikalitas } \\
\mathbf{( \% )}\end{array}$ & Ketegori \\
\hline 1 & Kelayakan Tampilan & $82,50 \%$ & Sangat Praktis \\
\hline 2 & Penyajian Materi & $84,29 \%$ & Sangat Praktis \\
\hline 3 & Manfaat & $83,54 \%$ & Sangat Praktis \\
\hline \multicolumn{2}{|c|}{ Rata-rata } & $\mathbf{8 3 , 4 4 \%}$ & Sangat Praktis \\
\hline
\end{tabular}

Dapat dijelaskan dari hasil uji praktikalitas pengerajin/peserta pelatihan kelompok kecil sebagai berikut: 1) kelayakan tampilan dengan hasil 82,50\% kategori sangat praktis, 2) penyajian materi dengan hasil 84,29\% kategori sanagt praktis, 3) manfaat dengan hasil 83,54\% kategori sangat praktis. Dari 3 aspek penilaian di atas diproleh rata-rata $83,44 \%$ dengan sangat praktis.

Hasil uji praktikalitas pengerajin/peserta pelatihan kelompok besar setelah dilakukan uji praktikalitas pengerajin/peserta pelatihan kelompok kecil, kemudian dilakukan uji prakatikalitas pengerajin/peserta pelatihan kelompok besar. Dengan memberikan angket kepada 25 orang pengerajin/pesertapelatihan.

Tabel 3. Hasil Uji Praktikalitas Pengerajin/ Peserta Pelatihan Kelompok Besar

\begin{tabular}{|c|l|c|c|}
\hline No & \multicolumn{1}{|c|}{ Aspek Penilaian } & $\begin{array}{c}\text { Hasil } \\
\text { Praktikalitas } \\
\mathbf{( \% )}\end{array}$ & Kategori \\
\hline 1 & Kelayakan Tampilan & $86,94 \%$ & Sangat Praktis \\
\hline 2 & Penyajian Materi & $84,17 \%$ & Sangat Praktis \\
\hline 3 & Manfaat & $85,56 \%$ & Sangat Praktis \\
\hline \multicolumn{2}{|c|}{ Rata-rata } & $\mathbf{8 5 , 5 6 \%}$ & Sangat Praktis \\
\hline
\end{tabular}

Dapat diuraikan dari 3 as pek penilaian uji praktikalitas kelompokbesar sebag ai berikut: 1) kelayakan tampilan dengan hasil 86,94\% kategori sangat praktis, 2) penyajian materi dengan hasil $84,17 \%$ kategori sangat praktis, 3) manfaat dengan hasil $85,56 \%$ kategori sangat praktis. Dari hasil penilaian tersebut diproleh rata-rata $85,56 \%$ dengan kateg ori sang at praktis.

\section{Pembahas an}

Nama batik berasal dari kata "mba" dan "tik" yang berarti membuat titik-titik. Seiring dengan pendapat diatas, 9) batik adalah teknik melukis diatas kaian dengan menggunakan malam dan canting. Malam digunakan sebagai perintang warna agar tidak meluar pada area yang tidak diinginkan. 10) Batik itu sendini merupakan warisan budaya yang menjadi identitas bangsa dan harus dilestarikan. Kain batik digemari oleh 


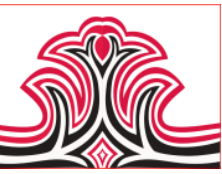

masyarakat luas, yang dipakai sebagai busana, perlengkapan rumah tangga, benda-benda kriya lainnya. Batik memiliki nilai tradisi buday a Nusantara yang sangat berharga karena kriya batik telah mampu mengangkat derajat budayabangsa ke arena persaingan dunia teks tildi Mancanegara, karena kualitan etnis dan teknis, serta berbagai keunikannya. 11) Batik berhubungan erat dengan agama seperti yang terlihat dalam motifnya yang dipengaruhi oleh Hindu dan Is lam, oleh budaya Cina dan Eropa; tetapi sekaligus pada saat yang sama agama tidak membatasi kehadiran berbagaimotif'. Oleh sebab itu, batik merupakan seni budaya yang mengandung nilai-nilai filosofi masyarakat, yang merupakan perpaduan konsep agama, kepercayaan dan budaya.

Dari pendapat diatas dapat dis impulkan bahwa, batik merupakan suatu produk tekstil yang terbuat dari serat tumbuhan atau ulat sutra. Batik merupakan hasil proses penutupan pori-pori mori (kain) dengan lilin (malam) dipermukaan mori (kain) menggikuti motif. Kain batik adalah salah satu wujud kebangaan masyarakat Indonesia terhadap waris an budaya bangsa, (12). PBB (UNESCO) resmi mengakui batik sebagai warisan dunia tak benda (intangibele) yang berasal dari Indonesia, Oktober 2009”. Pengakuan UNESCO atas Batik sebagai warisan dunia yang berasal dari Indonesia tidak permanen sifatnya. Status tersebut dapat berakhir jika Bangsa Indonesia sebagai pewanis tradisi seni.

Dalam eks perimen tahap pertama ini alat yang dipakai untuk membatik adalah canting cap, wajan, kompor, dan meja atau bantalan untuk membatik, serta kuas untuk mencolet. Dibawah ini diuraikan satu persatu: Canting merupakan utama yang dipakai untuk membatik s aat ini. Cating ada dua macam; canting cap dan canting tulis. Canting tulis berupa alat kecil yang terdiri dari cucuk, nyamplungan (wadah untuk mengambil cairan malam) dan bambu sebagai pegangannya. Canting merupakan alat utama untuk membuat batik tulis. Canting tidak perlu dibuat sendiri, karena bany ak dijual dipasar.

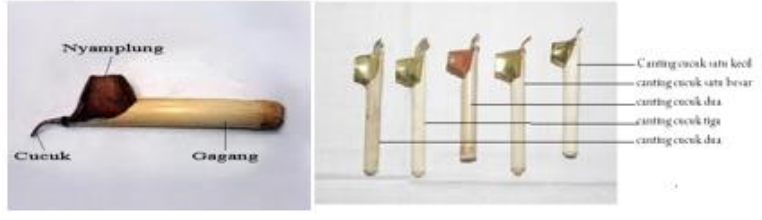

Gambar 1. Canting Tulis (Sumber: Nita Sahara, 2019)

Jenis canting tulis yang dipakai untuk membuat batik sangat menentukan kehalusan dan kerapian hasil
Gorga : Jurnal Seni Rupa

Volume 09 Nomor 01 Januari-Juni 2020

p-ISSN: 2301-5942 | e-ISSN: 2580-2380

pekerjaan. Canting ada beberapamacam sesuai fungsi, ukuran dan banyakny a cucuk. Canting tersebut dapat dibedakan sebagai berikut : (1) Menurut fung sinya ada dua macam yaitu Canting Reng-rengan, bercucuk sedang dan tunggal di pergunakan kusus untuk membuat pola, dan Canting Isen, bercucuk kecil dipergunakan untuk membatik is i bidang atau mengisi pola. (2) Menurut ukurannya cucuk canting terdiri dan canting carat/ cucuk kecil, sedang dan besar dan (3)Menurut banyaknya cucuk, yaitu Canting Cecekan (bercucuk satu kecil), Canting Loron (bercucuk dua berjalar), Canting Talon (bercucuk tiga), Canting Prapatan, (bercucuk empat), Canting Liman (bercucuk lima), Canting Byon (bercucuk tujuh atau lebih ters usun lingkaran), dan Canting Rentengan (bercucuk genap tersusun daribawah ke atas).

Canting cap dibuat berdasarkan motif desain batik inovasi ragam hias ukiran Minangkabau yang telah dides ain oleh timpeneliti. Untuk membuat canting cap diperlukan waktu lebih kurang satu bulan. Hasil pembatikan dipengaruhi oleh kesempurnaan bentuk canting. Canting cap dapat dibuat dengan mengupahkan pada tukangnya sesuai dengan desain y ang diinginkan dan tidak perlu membuat sendiri .

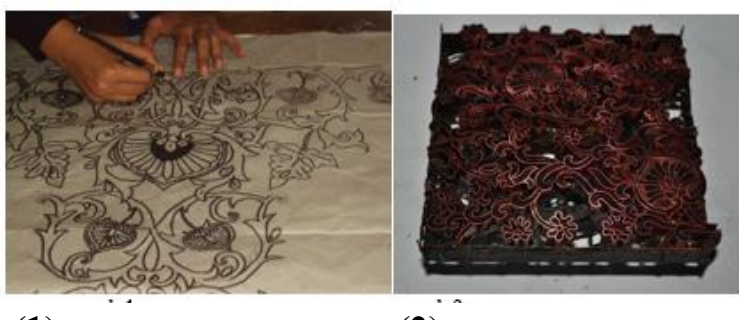

(1)

(2)

Gambar 2. Mengembangkan Motif Ukir Menjadi Motif Baik (1) dan Canting Cap dengan Motif Inovasi Ukiran Minangkabau (2) (Sumber: Nita Sahara, 2019)

Gawangan dipakai untuk membentangkan mori yang sudah dicanting agar tidak retak dan gawang juga digunakan untuk mencolet. Gawangan dibuat dari bahan bambu berbentuk persegi panjang. Gawangan berfung si untuk menyangkutkan kain ketika membatik. Bentukgawangan yang digunakan dalamkarya inovasi ini dapat dilihat padagambar dibawahini.

Wajan yang digunakan dalam eksperimen ini adalah wajan yang berbentuk datar yang berdiameter $40 \mathrm{~cm}$, yang berfungsi untuk memanaskan malam. Wajan terbuat daribahan tembaga atau malam. Kompor yang dipakai untuk memanaskan malah adalah kompor gas dengan panas api yang kecil.

Kuas dipergunakan untuk mewarnai batik dengan sistem colet. Kuas digunakan berdasarkan kebutuhannya. Untuk motif yang kecil-kecil 
Gorga : Jurnal Seni Rupa

Volume 09 Nomor 01 Januari-Juni 2020

p-ISSN: 2301-5942 | e-ISSN: 2580-2380

menggunakan kuas y ang berukuran kecildan pada saat mewarnai motif yang sedang dan untuk motif besar menggunakan kuas yang berukuran sedang dan besar pula. Dalam membatik ada beberapa bahan yang digunakan, yang termas uk bahan pembuat an batik yaitu mori, malam batik dan pewarna batik. Mori meru pakan bahan utama untuk membatik, berbagai bahan mori dapat dipergunakan, antara lain: katun primisima, katun prima, sutra, dobi cina, blacu, dan viscos.

Tujuan menggunakan bahan yang beragam dalam uji coba ini adalah untuk melihat hasil dari inovasi dari masing-masing bahan. Malam digunakan sebagai bahan untuk menutup bagian mori yang belum diwarnai motif yang telah ditentukan. Malam yang digunakan empat macam sesuai menurut sifat dan kegunaannya sebagai berikut ini. (1) Malam carik, warnanya agak kuning, sifatnya lentur tidak mudah retak lekatnya hebat, gunanya untuk membuat batik tulis halus. (2) Malam gambar, warnanyakuning pucat, sifatnya mudah retak, gunanya ialah untuk membuat remekan (efek warna retak). (3) Malam tembokan, warnany a agak coklat sedikit, sifatnya kental, gunanya untuk menutup blok (putih). (4) Malam biron, warnanya lebih coklat lagi, gunanya untuk menutup atau menembok. Zat warna yang digunakan yaitu zat warna procion.

Zat Warna procion dipilih sebagai bahan pewamaan colet karena zat warna ini mudah menghasilkan wama. Sebelum dicolet serbuk procion di larutkan terlebih dahulu dengan campuran soda kue, tepol dan air hangat. Soda kue dan tepol berfungsi untuk membuka pori-pori mori sehingga memperlancar penyerapan warna. Selain warna yang dihasilkan dari beberapa zat warna procion yang sudah ada, warna juga dapat dihasilkan dengan cara mencampurkan beberapa zat warna procion yang berbeda. Oleh sebab itu zat warna yang akan digunakan harus dibuat sesuai kebutuhan karena setiap percampuran warna belum tentu menghasilkan warna yang s ama.

Pada tahap persiapan yang dilakukan adalah mempersiapkan semua peralatan dan bahan yang diperlukan. Mempersiapkan mori merupakan faktor utama dalam menghasilkan batik yang berkualitas. Oleh sebab itu, sebelumdibatik yang dilakukan adalah, mengukur dan menggunting mori, merendam (ngetel), menjemur mori, dan memukul mori dengan pemukul kayu (ngemplong). Langkah-langkah membatik yang dilakukan, dapat dikelompokan menjadi tiga tahap, yang diuraikan pada tabel berikut:
Tabel 1. Tahapan dalam Membatik

\begin{tabular}{|c|c|}
\hline 1. Persiapan & $\begin{array}{l}\text { a) Mempersiapkan semua peralatan } \\
\text { b) Mempersiapkan bahan }\end{array}$ \\
\hline 2. Pembatikan & $\begin{array}{l}\text { a) Merendam mori selama satu malam, } \\
\text { untuk menghilangkan lilin pada mori } \\
\text { b) mencantingkan malam pada mori } \\
\text { dengan menggunakan canting cap } \\
\text { c) Merendam mori ke dalam cairan } \\
\text { tepol } \\
\text { d) Mewarnai dengan telnik pencelupan } \\
\text { e) Mengeringkan mori } \\
\text { f) Mencolet wama } \\
\text { g) Menembok wama (jika diperlukan) } \\
\text { h) Mencelup maupun mencolet } \\
\text { dilakukan sesuai jumlah warna yang } \\
\text { diinginkan. }\end{array}$ \\
\hline 3. Penyelesaian & $\begin{array}{l}\text { a) Menghilangkan lilin dengan teknik } \\
\text { melorod } \\
\text { b) Mengeringkan mori } \\
\text { c) Melipat dan menyimpan hasil } \\
\text { pembatikan. }\end{array}$ \\
\hline
\end{tabular}

Ukiran pada umumnya terdapat pada dinding dan papan panel sebelah luar. Pada bagian dalam tidak diukir, kalaupun diukir hanya di beberapa tempat tertentu saja, seperti pada pintu dan jendela beserta ventilas inya. Pengembangan dis esuikan deng an teknik membatik. Ragam hias ukiran menjadi ragam hias batik tidak bisa dipindahkan secara lansung, perlu penyesuaian dan perubahan garis dan bentuk sesuai dengan teknik membatik. Di bawah ini disenaraikan nama-nama motif ukiran Minangkabau dan motif ukiran Minangkabau pada tabelberikut: 


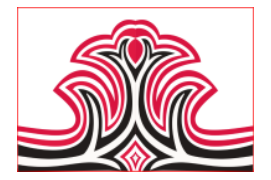

Tabel 2. Nama-nama Motif Ukiran Minangkabau

\begin{tabular}{|c|c|c|}
\hline Flora & Fauna & Benda lainnya \\
\hline $\begin{array}{l}\text { - Aka bapilin } \\
\text { - Aka baravun } \\
\text { - Aka Cino } \\
\text { - Aka duo gagang } \\
\text { - Aka sagagang } \\
\text { - Buah pinang } \\
\text { - Bungo cangkeh } \\
\text { - Buah kaladi } \\
\text { - Bungo duo tangkai } \\
\text { - Bungo labu } \\
\text { - Bungo panco matoari } \\
\text { - Bungo pitulo } \\
\text { - Bungo lado } \\
\text { - Bungo mangavang } \\
\quad \text { buah } \\
\text { - Bungo mantimun } \\
\text { - Bungo taratai } \\
\text { - Daun bodi } \\
\text { - Daun kacang Goreng } \\
\text { - Daun puluik-puluik } \\
\text { - Daun saksk } \\
\text { - Daun satanghai } \\
\text { - Daun siriah } \\
\text { - Kalayau } \\
\text { - Kambang perak } \\
\text { - Kaluak paku } \\
\text { - Kapeh kambang } \\
\text { - Laviahjarami } \\
\text { - Lumuik hanvuik } \\
\text { - Pisang sasikek } \\
\text { - Picuak rabuang } \\
\text { - Rantiang tasalek } \\
\text { - Salimpat } \\
\text {-Siriah sagagang } \\
\text {-Tampuak manggih }\end{array}$ & $\begin{array}{l}\text { - Alang babega } \\
\text { - Bada mudiak } \\
\text { - Bavabah mandi } \\
\text { - Gajah badorong } \\
\text { - Harimau dalam parangkok } \\
\text { - Itiak pulang patang } \\
\text { - Kalalawa bagquik } \\
\text { - Kijang balavi } \\
\text { - Kuciang lalok } \\
\text { - Kudo manyipak } \\
\text { - Kunang-kumang } \\
\text { - Limpapoh } \\
\text { - Labah mangirok } \\
\text { - Lokan-lokan } \\
\text { - Paruah anggang } \\
\text { - Ramo-ramo } \\
\text { - Ruso balari } \\
\text { - Siku kalalawa } \\
\text { - Sikumbang janti } \\
\text { - Sipadeh manyasok bungo } \\
\text { - Takuak kudo manyipak } \\
\text { - Tantadu bararak } \\
\text { - Tantadu manyasok bungo } \\
\text { - Tupai managun } \\
\text { - Ula gerang } \\
\text { - Singo mandongkak }\end{array}$ & $\begin{array}{l}\text { - Ampiang taserak } \\
\text { - Carano kanso } \\
\text { - Dama tivih } \\
\text { - Tangguak lamah } \\
\text { - Jarek takaka } \\
\text { - Kaluak laka } \\
\text { - Kambang sitinjau lauik } \\
\text { - Kambang paposikumbang } \\
\text { - Lapiah ampek } \\
\text { - Maniak javang } \\
\text { - Pesong aia buiah } \\
\text { - Puti ambun swi } \\
\text { - Rajo saavi } \\
\text { - Saik galamai } \\
\text { - Sajamba makan } \\
\text { - Saok kapuran } \\
\text { - Sanggan uran pasaka } \\
\text { - Siganjo lalai } \\
\text { - Sikambang manih } \\
\text { - Sitinjau lauik } \\
\text { - Tanguak lamah } \\
\text { - Tivai-tivai } \\
\text { - Tirai ampek angkek } \\
\text { - Jambua cawek } \\
\text { rang pitalah }\end{array}$ \\
\hline
\end{tabular}

Tabel 3. Motif-motif Ukiran Minangkabau sebagai Sumber Inspirasi

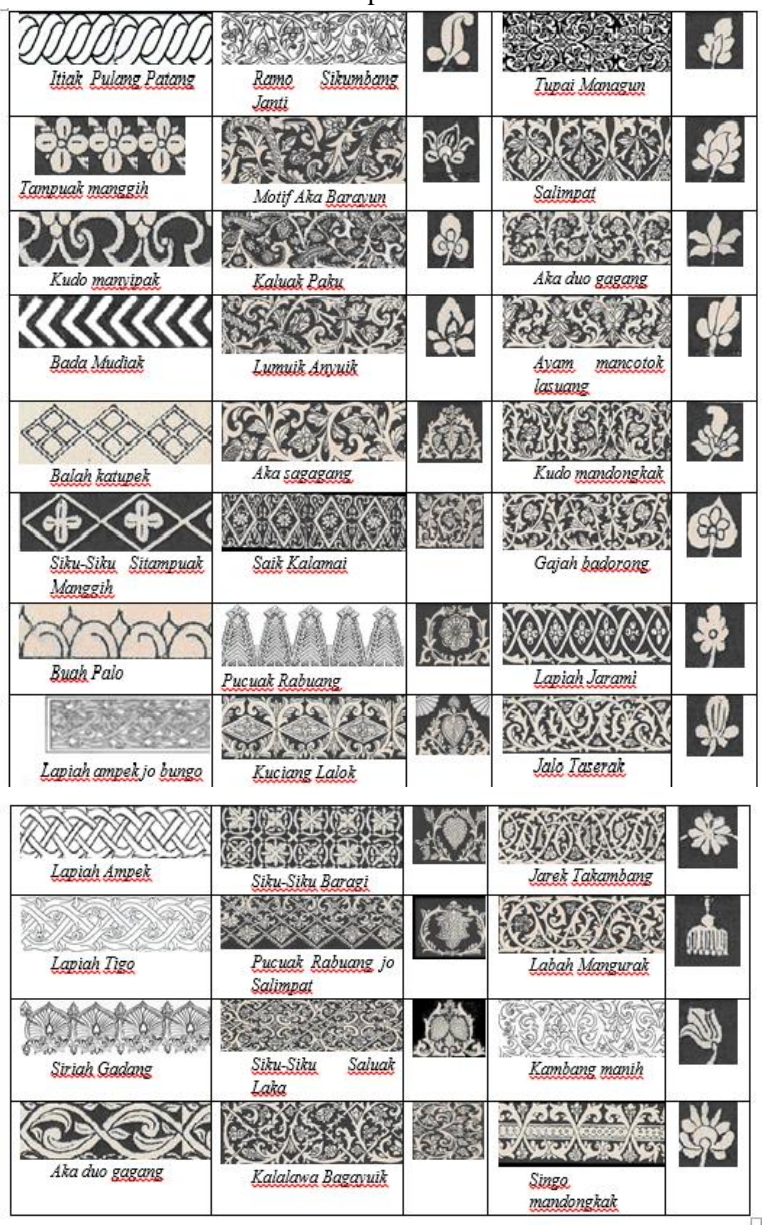

Gorga : Jurnal Seni Rupa

Volume 09 Nomor 01 Januari-Juni 2020

p-ISSN: 2301-5942 | e-ISSN: 2580-2380

Dalam mendesain motif ukiran menjadi motif batik perlu penyesuaian-penyesuaian bentuk. Media yang dipakai untuk ukiran dengan batik jauh berbeda, pada ukiran media yang dipakai adalah kayu sedangkanpada batik media yang dipakai adalah mori (tekstil untuk batik), oleh sebab itu motif ukiran perlu di stilir dan disesuaikan dengan karater motif batik dengan langkah sebagai berikut: Motif yang ada pada ukiran diurai satu per satu dan dianalisis bentuk dan karakternya. Penggabungan motif dilakukan dengan melihat bentuk, karakter, dan filosofi yang sama atau hampir mendekati. Misalnya, motif kaluak paku tidak bisa dis atukan dengan motif ayam macotok lasuang, karena kedua motif ini bertentangan filos ofinya. Kaluak paku simbol kepemimpinan yang bijaksana, sedangkan ayam mancotok lasuang simbol kehidupan yang tidak memikirkan orang lain atau hanya mementingkan diri sendiri.

Motif yang dig ambar direngga dan dipilah-pilah mana yang memiliki karakter dan filosofi yang sama atau saling berkaitan. Tujuang mengelompokan Motif diubah sesuai dengan penataan motif batik dan tata letak pada pakaian. Pada tahap ini dilakukan uji motif dan kesesuaian motif pada pakaian. Bentuk dan tata letak desain yang dianggap tepat ditambahkan dengan isen isen. Pada karya kreatif ini sebagai isen-isen pengisi ruang dipakai motif tenunan songket Minangkabau atau bentuk salur dan bunga-bungakecil yang biasaterdapat pada ukiran Minangkabau.

Langkah selanjutnya adalah menempatkan motif pada kain dan juga membuat batik dengan menyesuaikan dengan pola pakaian atau menyusun tata letak motif pada badan. Pada tahap ini, juga dilakukan kaji ulang, apakah motif sudah dianggap seimbang dan sesuai dengan komposisi yang diharapkan. Pada tahap ini, jika diper perlukan melakukan renovasi kembaliterhadap motif yang sudah dibuat, karena belum memenuhi kreteria yang diharapkan, dilakukan renovasi bahkan perubahan total pun dilakukan. Desain yang sudah dianggap, dilanjutkan deng an pemindahan motif pada mori (bahan dasar yang akan dibatik), dan setelah itu dilakukan pembatikan. Eksperimen dilakukan berulangkali sampai ditemukan batik yang benar-benar seperti yang diharapkan. Maka untuk mendapakkan bahan aja yang layak dan dapat dipergunakan perlu dilakukan uji kelayakan.

\section{KESIMPULA DAN SARAN 1.Kesimpulan}

Pengembangan bahan ajar untuk pelatihan batik pada pelatihan batik di UKM sebagai mitra dapat dipergunakan karena telah melalui uji kelayakan. 
Tahap uji validitas bahan ajar batik untuk usaha kecil menengah (UKM) hasil penilaiannya adalah 83,35\% dinyatakan sangat valid jadi layak untuk dipergunakan. Tahap uji prkatikalitas bahan ajarbatik tulis padamata kuliah analisis tekstil yang diproleh dari respon pengerajin/peserta pelatihan dan dosen pembina mata kuliah hasil penilaian uji praktikalitas yang diproleh adalah $85,89 \%$ dinyatakan sangat praktis untuk di gunakan.

\section{Saran}

Kegiatan pelatihan yang dilaksanakan ini sangat besar manfaatnya bagi perkembangan seni tradisi Minangkabau. Langkah ini juga sebagai upaya kesenian untuk mengenalkan dan melestarikan kebudayaan Minangkabau secara khusus batiknya.

\section{DAFTAR RUJUKAN}

Dhani, S.R., Wiratma, S., Mis giya, M. (2020). Tinjauan Hasil Kerajinan Batik Cap di Batik Sumut Medan TembungBerdasarkan Warna Motif dan Harmonis asi. Gorga : Jurnal Seni Rupa, 9(1), 88-93.

Elliott, Inger McCabe. (1984) Batik: fabled clothof

Java photographs, Brian Brake ; contributions, Paramita Abdurachman, Susan Blum, Iwan Tirta; design, Kiyoshi Kanai. New York: Clarks on N. Potter Inc.

Kartono, G., Mesra, M., \& Azis, A. C. K. (2020). pengembangan media Ajar Grafis Komputer Materi WPAP dalam Bentuk E-book dan Video Tutorial bagi Mahasiswa Seni Rupa. Gorga: Jurnal Seni Rupa, 9(1), 127132.

Prasetyo, S. A. (2016). Karakteristik motif batik Kendal interpretasi dari wilayah dan letak geografis . Imajinasi: Jurnal Seni, 10(1), 5160. 